\title{
Comunicación

\section{Redes sociales, participación ciudadana y democracia: una perspectiva realista sobre las oportunidades del digi-activismo}

EMILIANO TRERÉ1

Se han utilizado ríos de tinta para describir y analizar el papel que las redes sociales desempeñan en los estallidos y las protestas sociales que a partir del año 2011 impactan el mundo en diversas latitudes. Estas revoluciones han vuelto a polarizar excesivamente el ya controvertido debate sobre el potencial emancipador y los límites de las plataformas digitales para las democracias contemporáneas, ensanchando aún más la brecha entre optimismo y pesimismo digi-activista (Waisbord, 2015). El nuevo libro de María Elena Meneses Rocha representa una interesante contribución a este debate. Doctora en Ciencias Políticas y Sociales por la Universidad Nacional Autónoma de México (UNAM); ex periodista de televisión en medios nacionales e internacionales, $\mathrm{y}$

1 Universidad Autónoma de Querétaro, México/Lakehead University, Canadá. Correo electrónico: emiliano.trere@uaq.mx

Cerro de las Campanas S/N, C.P. 76010; Santiago de Querétaro, Querétaro, México. 
consejera de la Fundación Mexicana de Periodismo de Investigación (FMEPI), la doctora Meneses es directora de la revista electrónica Virtualis y colabora como articulista en temas de medios de comunicación, periodismo y cultura digital. Actualmente, dirige la "Cátedra Sociedad de la Información y del Conocimiento" en el Instituto Tecnológico y de Estudios Superiores de Monterrey (ITESM), campus Ciudad de México. Es autora de Periodismo Convergente: Tecnología, Medios y Periodistas en el Siglo XXI (2011) y coautora de Internet y campañas electorales en México. La oportunidad postergada (Meneses \& Bañuelos, 2011).

En Ciberutopías. Democracia, Redes Sociales, Movimientos-Red, la autora adopta un enfoque realista y ofrece una amplia revisión de la literatura sobre las oportunidades que les abre Internet y, en particular las redes sociales, a las democracias contemporáneas. Bajo esta perspectiva, la profesora del ITESM analiza el movimiento social \#YoSoy132, gestado desde las redes sociales durante el proceso electoral presidencial mexicano del año 2012. Meneses argumenta que, pese a las nuevas oportunidades que estas tecnologías están brindando, las plataformas digitales siguen siendo insuficientes para garantizar una participación política plena y trascendental.

El libro está estructurado en cuatro capítulos. En el primero de ellos, la autora revisa críticamente las principales posturas acerca del papel de las tecnologías digitales y la democracia. Meneses introduce desde las primeras páginas su visión realista, una postura que reconoce tanto las contribuciones como los obstáculos, y las limitaciones de los social media para la participación ciudadana. Así mismo, la autora inserta las oportunidades de las redes sociales dentro de un contexto económico y político complejo, impactado por cuestiones relacionadas con la desconexión y la falta de oportunidades de acceso, y marcado por la censura y la omnipresente vigilancia gubernamental y corporativa de empresas como Facebook y Google. En el segundo capítulo, Meneses articula un esquema con dimensiones de involucramiento ciudadano mediante las redes sociales. A través de este modelo pretende aclarar cuáles son las características principales de la participación en las plataformas online y al mismo tiempo especificar las diferencias respecto de las prácticas más tradicionales de partici- 
pación política (votar, pertenecer a un partido, etc.). La autora discute también las problemáticas que se originan a partir de la paradoja de utilizar plataformas corporativas privadas de dudosa transparencia para contribuir a la vida pública. Durante el tercer capítulo introduce el caso de análisis de su obra: el movimiento estudiantil \#YoSoy132. La académica del ITESM proporciona una cronología basada en un análisis de textos periodísticos, observación y testimonios, en la cual enseña el poder de las redes sociales como espacios autónomos donde los ciudadanos comunican, se auto-organizan y movilizan. En el cuarto y último capítulo continúa y termina su análisis del movimiento mexicano, esta vez mediante la interpretación de las experiencias de algunos de sus protagonistas destacados.

El libro de Meneses tiene el gran mérito de realizar lo que varias obras no han logrado hacer: trascender el caso específico del movimiento estudiantil mexicano, para llegar a insertar las reflexiones sobre el papel de las plataformas digitales dentro de la literatura nacional e internacional. Por esta razón, su libro apela a un público muy amplio, y puede convertirse en una referencia fundamental sobre todo para estudiantes de licenciaturas, maestrías y doctorados en ciencias sociales, políticas, estudios culturales, periodismo y comunicación. Además, mediante su original análisis etnográfico del movimiento \#YoSoy132 a través de las voces de algunos de sus actores claves, Meneses nos ofrece una exploración equilibrada y razonada acerca del surgimiento y del desarrollo del movimiento mexicano: una investigación sofisticada que huye tanto de la entusiasta celebración que ha caracterizado una parte de la academia, como de las críticas partidarias a priori de un considerable segmento de la prensa. Si se puede hacer una crítica a esta obra es la de no representar un atrevido esfuerzo de innovación conceptual, no proponer ningún paradigma nuevo ni presentar un modelo original explicativo sobre la relación entre redes digitales y democracia -ambiciosa tarea, en el núcleo de obras como el último trabajo de Bennett y Segerberg (2013)-. Su contribución principal reside en su capacidad de revisar con sentido crítico las dimensiones más relevantes de varios años de investigación acerca de un tema actual y controvertido, pero, en lugar de avanzar hacia tierras inexploradas y más "peligrosas" desde 
el punto de vista académico, la obra prefiere recorrer caminos ya transitados y utilizar metáforas más experimentadas como la afortunada equivalencia movimientos $=$ redes. ${ }^{2}$

En definitiva, estamos ante una obra valiosa que contribuye tanto al debate sobre el verdadero potencial democratizador del digi-activismo, como a la discusión sobre el aporte de las redes digitales dentro del movimiento \#YoSoy132, a través de una perspectiva crítica bien fundamentada en la literatura y un minucioso trabajo etnográfico.

\section{Bibliografía}

Bennett, W. L. \& Segerberg, A. (2013). The logic of connective action: Digital media and the personalization of contentious politics. Cambridge, Inglaterra: Cambridge University Press.

Meneses, M. E. (2011). Periodismo convergente: tecnología, medios y periodistas en el siglo XXI. México: Porrúa.

Meneses, M. E. \& Bañuelos Capsitrán, J. (2011). Internet y campañas electorales en México: la oportunidad postergada. Toluca, México: Instituto Electoral del Estado de México.

Rovira Sancho, G. (2012). Movimientos sociales y comunicación: la red como paradigma. Anàlisi, 45, 91-104.

Waisbord, S. R. (2015). El optimismo digi-activista y sus problemas. En A. Amado \& O. Rincón (Eds.), Re-invención de los discursos de la comunicación. Bogotá, Colombia: Fundación Ebert.

2 Para profundizar en el análisis de la red como paradigma de los movimientos sociales y de la comunicación, véase Rovira Sancho (2012). 